\title{
Proportion and characteristics of patients with Type 2 diabetes mellitus initiating basal insulin therapy using a basal-bolus regimen
}

Puhong Zhang ( $\square$ zpuhong@georgeinstitute.org.cn )

The George Institute for Global Health at Peking University Health Science Center

https://orcid.org/0000-0003-4610-9848

\section{Heng Zhang}

The George Institute for Global Health at Peking University

Dongshan Zhu

The George Institute for Global Health at Peking University

\section{Xian Li}

The George Institute for Global Health at Peking University

Jiachao Ji

The George Institute for Global Health at Peking University

\section{Minyuan Chen}

The George Institute for Global Health at Peking University

\section{Du Wang}

The George Institute for Global Health at Peking University

Linong Ji

Department of Endocrinology and Metabolism, Peking University People's Hospital

\section{Research article}

Keywords: Type 2 diabetes mellitus, basal insulin initiation, basal-bolus insulin, intensive insulin therapy, glycemic control

Posted Date: December 20th, 2019

DOI: https://doi.org/10.21203/rs.2.19406/v1

License: (1) (1) This work is licensed under a Creative Commons Attribution 4.0 International License. Read Full License 


\section{Abstract}

Background: To explore the proportion and characteristics of patients with Type 2 diabetes mellitus (T2DM) uncontrolled by oral antidiabetic drugs (OADs) who initiated basal insulin (BI) therapy using a basal-bolus regimen.

Methods: This multicenter, observational, prospective study included a representative sample of 18,995 Chinese insulin-naïve T2DM patients who initiated BI therapy due to uncontrolled hyperglycemia by OADs. The type and dose of $\mathrm{BI}$ as well as other treatment regimens depended on physician's discretion and patient's willingness. Proportion of patients initiating basal-bolus insulin and associated factors were analyzed.

Results: Basal-bolus accounted for $24.6 \%$ of patients initiating Bl, of whom $97.8 \%$ initiated a full basalbolus regimen. In the multivariate logistic regression, factors significantly associated with initiating basalbolus regimen were tertiary hospital, in-patients, younger age, higher BMI, longer diabetes duration, more complications, higher $\mathrm{HbA1c}$ level, low self-monitoring of blood glucose (SMBG) frequency before, one OAD used before, no concomitant OAD, and initiating Neutral Protamine Hagedorn (NPH). About half of patients initiating basal-bolus persisted on the same insulin regimen at 3-month. Glycemic control rates $(\mathrm{HbA} 1 \mathrm{c}<7 \%)$ at 6 months were $37.6 \%$ and $41.8 \%$ in basal-bolus and $\mathrm{BI}$ alone, respectively $(\mathrm{p}<0.0001)$. In patients with at least one complication, basal-bolus showed significantly lower glycemic control compared with $\mathrm{BI}$ alone (33.4\% vs $39.8 \%, \mathrm{P}<0.0001)$.

Conclusions: The findings suggest a high proportion of patients with T2DM initiating basal-bolus insulin. Tertiary hospital, in-patients, younger age, higher BMI, longer diabetes duration, more complications, higher $\mathrm{HbA1c}$ level, low SMBG frequency before, one OAD used before, no concomitant OAD, and concomitant NPH were related to higher odds of initiating basal-bolus.

\section{Background}

Type 2 diabetes mellitus (T2DM) as the main form of diabetes features a progressive decline of beta-cell function presented usually by the time of diagnosis, resulting in a progressive disorder of glycemic metabolism. ${ }^{(1,2)}$ Previous studies have suggested that prompt initiation of therapy and achieving glycemic targets early in the disease course can reduce the risk of adverse complications, owing to less damage from hyperglycemia. ${ }^{(3-6)}$ However, it was estimated that only $25.8 \%$ of Chinese T2DM were treated for diabetes, and only $39.7 \%$ of those treated had sufficient glycemic control. ${ }^{(7)}$

The current guidelines recommend stepwise treatment intensification for maintaining optimal glucose control in T2DM. ${ }^{(8,9)}$ When OADs in addition to lifestyle management fail to maintain adequate glycemic control, the introduction of exogenous insulin is required. A basal insulin (BI) alone is typically added to OADs as initial insulin therapy unless the patient is markedly hyperglycemic and/or symptomatic, who will require the addition of bolus insulin to achieve appropriate glycemic targets eventually. ${ }^{(10)}$ 
Given that the stepwise addition of bolus insulin to $\mathrm{Bl}$ is usually suggested when $\mathrm{HbA1c}$ remains suboptimal after initiating $\mathrm{BI}^{(11)}$ initiating basal-plus or full basal-bolus might imply a greater delay of insulin therapy than a single injection of $\mathrm{BI}$ when initiating BI. Moreover, there is a dearth of studies on how $\mathrm{BI}$ is initiated among Chinese T2DM in large-scale real-world settings. The aim of this study was to determine the status and associated factors of patients using basal-bolus as $\mathrm{BI}$ initiation regimen in a large nationally representative sample of Chinese T2DM who initiated BI due to insufficient glycemic control on OADs.

\section{Methods}

\section{Study design and population}

The present study was part of Observational Registry of Basal Insulin Treatment (ORBIT), ${ }^{(12)}$ which was a 6-month multicenter and prospective observational study in eight geographic regions of China. The study design, sampling strategy, recruitment, questionnaire and examination components have been reported in detail previously. ${ }^{(12)}$

From December 2011 to December 2012, patients with T2DM who were failing on oral antidiabetic agents $(\mathrm{HbA} 1 \mathrm{c} \geq 7 \%)$ and willing to initiate $\mathrm{BI}$ treatment were consecutively recruited by their physicians in secondary and tertiary hospitals all over China. The type of BI and corresponding antidiabetic regimens used were at the physician's discretion and patient's willingness.

All participants provided written informed consent and confirmed their willingness to participate in this study. The study protocol was approved by the Institutional Review Board of Peking University and, when necessary, also approved by local Institutional Review Boards.

\section{Data collection}

Data from each participant were collected through study-specific records and traditional medical forms, consisting of baseline information on socio-demographic characteristics (age, gender, education level, and registered residence type), medical history (patient resources (out-patient or in-patient), diabetes diagnose date, OADs initiation date, type and dose of OADs used before, diabetes complications (coronary heart disease, stroke, peripheral vascular disease, diabetic kidney disease, diabetic retinopathy, peripheral neuropathy, and others), self-monitoring of blood glucose (SMBG), and hypoglycemia events), and current treatment regimen (type and dose of OADs and insulin); and follow-up data on SMBG, hypoglycemia events. A basal-bolus regimen was defined as being prescribed bolus insulin in addition to $\mathrm{Bl}$, where injecting bolus insulin 3 times per day was defined as a full basal-bolus regimen.

Physical examination (body height and weight) and laboratory test (fasting plasma glucose (FPG) and $\mathrm{HbA1c}$ ) were conducted according to a standard protocol and recorded at the baseline and 6-month. Body mass index (BMI) was calculated as weight in kilograms divided by height in meters squared. 


\section{Statistical analyses}

Descriptive statistics were calculated as frequencies (n) and percentages (\%) for categorical variables; means and SD for continuous variables. Chi-square tests and t-tests were used to assess differences in baseline characteristics between those with $\mathrm{BI}$ alone and those with basal-bolus.

A stepwise multivariate logistic regression model was used to identify factors associated with basalbolus as the $\mathrm{BI}$ initiation regimen. Variables included in the model were geographic region, hospital level (secondary or tertiary), patient recruitment setting (inpatient or outpatient clinic), age, gender, education level, type of registered residence (rural or urban), BMI, duration of diabetes, number of complications, $\mathrm{HbA1c}$, SMBG frequency, severe and general hypoglycemia, number of OAD types before and at baseline, and type of BI. Selection and deletion thresholds of variables in multivariate model were $p<0.10$ and $\mathrm{P}<0.15$, respectively.

Proportion of patients initiating basal-bolus were calculated stratified by having complications (yes or no), baseline HbA1c level ( $<9 \%$ or $\geq 9 \%$ ) and number of OADs used previously ( 1 or $\geq 2)$. Chi-square tests were used to analyze the statistical significance between the proportions of patients who reached $\mathrm{HbA} 1 \mathrm{c}$ target $(\mathrm{HbA} 1 \mathrm{c}<7 \%)$ at 6-month by insulin regimen groups (basal-bolus and $\mathrm{BI}$ alone) at baseline, stratified by having complications (yes or no), baseline HbA1c $(<9 \%$ or $\geq 9 \%)$ and number of OADs used previously ( 1 or $\geq 2$ ). Insulin regimen changes at 3-month and 6-month were also calculated in those initiating basal-bolus at baseline to illustrate the persistency of this regimen.

All statistical analyses were performed using SAS version 9.4 (SAS Institute, Cary, NC, USA). Statistical significance was set at $P<0.05$ using two-sided tests.

\section{Results}

\section{Baseline Characteristics}

The characteristics of participants by antidiabetic treatment regimens are shown in Table 1. Of the 18,995 eligible participants who initiated $\mathrm{BI}$ at baseline, $50.3 \%$ and $56 \%$ were from tertiary hospital and inpatient ward; mean age was 55.4 years; approximately half (52.5\%) of subjects were men; and $34.8 \%$ were agricultural registered residence. Mean diabetes duration was 6.4 years, and mean regular OAD treatment duration was 5.7 years. Mean $\mathrm{HbA} 1 \mathrm{c}$ and $\mathrm{FPG}$ were $9.6 \%$ and $11.7 \mathrm{mmol} / \mathrm{L}$, respectively.

\section{Insulin treatment regimens}

The proportion of patients initiating BI with basal-bolus regimen was $24.6 \%$ (4674/18995), with the overwhelming majority $(97.8 \%, 4569 / 4674)$ of patients initiating a full basal-bolus regimen. Types of initiating BI were mainly glargine, accounting for $70.0 \%$, whereas detemir and NPH accounted for $12.6 \%$ and $17.5 \%$, respectively. (Table 1 ) Mean BI dose and bolus insulin dose were $0.2 \mathrm{U} / \mathrm{kg} /$ day and 0.4 $\mathrm{U} / \mathrm{kg} /$ day, respectively. 
Of the 4,674 patients initiating basal-bolus, 4,252 and 3,983 were followed at 3-month and 6-month, in which $51.2 \%$ and $40.1 \%$ persisted on this regimen at 3-month and 6-month, whereas others switched to $\mathrm{BI}$ only (18.5\% at 3-month, $20.4 \%$ at 6 -month), only bolus insulin (2.0\% at 3-month, $2.3 \%$ at 6 -month), or premix insulin (15.0\% at 3-month, $17.5 \%$ at 6 -month); or stopped insulin therapy (13.3\% at 3 -month, $19.8 \%$ at 6-month). (Figure1a)

Of the 14,321 patients initiating BI only, 13,001 and 12,358 were followed at 3-month and 6-month, in which $86 \%$ and $79.6 \%$ persisted on this regimen at 3 -month and 6 -month, whereas others switched to premix insulin (1.9\% at 3-month, $2.9 \%$ at 6 -month), basal-bolus ( $0.7 \%$ at 3 -month, $0.9 \%$ at 6 -month), only bolus insulin ( $0.2 \%$ at 3 -month, $0.3 \%$ at 6 -month), or stopped insulin therapy $(11.2 \%$ at 3 -month, $16.3 \%$ at 6-month). (Figure1b)

\section{Factors associated with basal-bolus and its glycemic control}

Table 2 depicts multivariate logistic regression analyses with adjusted ORs and 95\% Cls for initiating the basal-bolus regimen. In the multivariate logistic regression, tertiary hospital, in-patients, younger age, higher BMI, longer diabetes duration, more complications, higher HbA1c level, low SMBG frequency, one OAD used before, no concomitant OAD, and initiating NPH were significantly associated with higher odds of initiating basal-bolus regimen.

After being stratified by having complications or not, and $\mathrm{HbA} 1 \mathrm{c}$ level $(<9.0 \%$ or $\geq 9.0 \%)$, patients with one $O A D$ used before were always associated with higher proportions of initiating basal-bolus compared with those with two or more OADs used before. (Table 3) Glycemic control rates (HbA1c<7\%) at 6 months were $37.6 \%$ and $41.8 \%$ in patients with basal-bolus and those with $\mathrm{BI}$ alone, respectively $(\mathrm{p}<0.0001)$.

In patients with no complication, the overall glycemic control rate was lower in those with basal-bolus than those with $\mathrm{BI}$ alone but with no significance (41.1\% vs $42.9 \%, \mathrm{P}=0.1262)$. Compared with $\mathrm{BI}$ only, basal-bolus showed significantly lower glycemic control rate in those with $\mathrm{HbA} 1 \mathrm{c}<9 \%$ and one OAD used before $(52.4 \%$ vs $58.5 \%, \mathrm{P}=0.0408)$, whereas it showed higher glycemic control rates in those with $\mathrm{HbA} 1 \mathrm{c}<9 \%$ and $\geq 2 \mathrm{OAD}(55.0 \%$ vs $48.1 \%, \mathrm{P}=0.0315), \mathrm{HbA} 1 \mathrm{c} \geq 9 \%$ and one OAD (41.4\% vs $37.9 \%$, $\mathrm{P}=0.0665)$, and $\mathrm{HbA} 1 \mathrm{c} \geq 9 \%$ and $\geq 2 \mathrm{OAD}(29.3 \%$ vs $28.9 \%, \mathrm{P}=0.8259)$. (Figure $2 \mathrm{a}$ )

In patients with at least one complication, the overall glycemic control rate was significantly lower in patients with basal-bolus than those with $\mathrm{BI}$ only $(33.4 \%$ vs $39.8 \%, \mathrm{P}<0.0001)$. Compared with $\mathrm{BI}$ only, basal-bolus showed lower glycemic control rates in those with $\mathrm{HbA1c}<9 \%$ and one OAD used before (44. $2 \%$ vs $54.5 \%, \mathrm{P}=0.0029), \mathrm{HbA} 1 \mathrm{c}<9 \%$ and $\geq 2 \mathrm{OAD}$ ( $41.5 \%$ vs $46.9 \%, \mathrm{P}=0.0948$ ), and $\mathrm{HbA} 1 \mathrm{c} \geq 9 \%$ and one OAD (30.9\% vs $34.2 \%, P=0.1880)$, except in those with $\mathrm{HbA} 1 \mathrm{c} \geq 9 \%$ and $\geq 2$ OAD (26.8\% vs $24.0 \%$, $P=0.2076$ ). (Figure $2 b$ )

\section{Discussion}


In this multicenter, observational study conducted in a nationally representative sample of T2DM patients with suboptimal glycemic control by OADs in China, approximately a quarter of patients initiated BI with a basal-bolus regimen, in which $97.8 \%$ initiated a full basal-bolus regimen. Patients initiating basal-bolus were mainly in-patients (81.5\%). Other factors associated with initiating basal-bolus were tertiary Hospital, younger age, higher BMI, longer diabetes duration, more complications, higher HbA1c level, low SMBG frequency, one OAD used before, no concomitant OADs and NPH insulin. Glycemic control rates $(\mathrm{HbA} 1 \mathrm{c}<7 \%)$ at 6 months were $37.6 \%$ and $41.8 \%$ in basal-bolus and $\mathrm{BI}$ only, respectively $(\mathrm{p}<0.0001)$. Compared with $\mathrm{BI}$ only, basal-bolus only showed significantly higher glycemic control in patients with no complications, baseline $\mathrm{HbA} 1 \mathrm{c}<9 \%$ and $\geq 2$ OADs used before (55\% vs. $48.1 \%, \mathrm{P}=0.0315)$.

The proportion (24.6\%) of initiating BI with the basal-bolus regimen in this study was higher than previous studies. One study by Kim et al. reported that basal-bolus insulin only accounted for $1.6 \%$ when initiating $\mathrm{Bl}^{(13)}$ whilst another study by Patrick et al. reported $13 \%$ patients using basal-bolus as the $\mathrm{BI}$ initiation regimen. ${ }^{(14)}$ In comparison, patients in the current study had a higher average $\mathrm{HbA1c}$ level (9.6\%) than Kim et al.'s study (9.2\%), ${ }^{(13)}$ whilst Chinese guidelines recommend initiating BI when $\mathrm{HbA} 1 \mathrm{C}$ $\geq 7 \%$ after 3 months of OAD treatment. ${ }^{(8)}$ Nevertheless, our study observed a mean diabetes duration of 6.4 years, which was shorter than previous studies ranging from 8.9 to 11.7 years. ${ }^{(11,13,15-17)}$ This might be due to a low proportion of early diabetes diagnosis since only $30.1 \%$ of Chinese diabetes patients were aware of their condition,(7) contributing to a severer hyperglycemia with a shorter duration of diagnosed T2DM. Accordingly, the high proportion of patients initiating basal-bolus insulin might be due to a previous late diagnosis of T2DM and delayed BI initiation in China.

Bolus insulin reduces postprandial glucose excursions, which was added to BI by two options: a stepwise approach or a full basal-bolus approach.(18) In the stepwise approach, bolus insulin is begun with one dose before the largest meal of the day and then progressively escalated to two and then possibly three pre-meal doses. In the full basal-bolus approach, three doses of bolus insulin were all added before each meal at a time. In our study, 97.8 percent of patients used a full basal-bolus regimen. It is possible that the majority of patients in our study needed a more intensive antidiabetic therapy to reach the glycemic target due to delayed insulin initiation, which could be reflected from the relatively high $\mathrm{HbA} 1 \mathrm{c}$ level at the baseline.

Although the full basal-bolus regimen might also offer an individualized treatment regimen through titration of bolus doses similar to the stepwise approach,(18) it would be initially challenging for some patients who had no insulin injection experience before to immediately transit from OADs to a complex regimen of 4-5 total daily injections of basal-bolus insulin. Moreover, the success of this regimen requires consistent carbohydrate intake counting for those who wish to vary their carbohydrate intake from meal to meal and day to day, which means that physicians should consider the patient's ability and willingness to track carbohydrate intake and perform the necessary, sometimes complex, calculations. $(19,20)$ Previous randomized clinical trials have observed that stepwise bolus insulin intensification achieved glycemic control non-inferior or close to a full basal-bolus regimen with significantly lower 
hypoglycemia risk, less weight gain and better patient satisfaction. $(21,22)$ Due to the fact that it would be burdensome for patients to comply with the full basal-bolus regimen, patient's adherence, insulin dose titration and SMBG should be emphasized for them. Moreover, approximately a half and $60 \%$ of patients initiating with basal-bolus switched to other insulin regimens after 3 months and 6 months, respectively. This might be because some physicians and patients especially those inpatients only used a short-term intensive insulin therapy and those hospitalized would switch to other insulin regimens after discharge from hospital.

In our study, $81.5 \%$ of patients using basal-bolus as the insulin initiation regimen were inpatients. It is reasonable that, compared with outpatients, hospitalized patients were mainly those with a higher glycemic level and more complications, therefore needing more intensive initial insulin therapy. While guidelines do not recommend one class or combination of medications over another for the management of hyperglycemia of outpatients, ${ }^{(23-25)}$ basal-bolus has been recommended as the preferred regimen in hospitalized patients in non-intensive care unit settings by clinical practice guidelines. ${ }^{(26,27)}$ Although many health care professionals are concerned about this regimen's inconvenience of implementation due to the high number of injections and risk of hypoglycemia, ${ }^{(28)}$ previous studies have showed that inpatient diabetes management using a basal-bolus regimen is effective and well tolerated. ${ }^{(29-32)}$

Our study indicated that more complications and higher $\mathrm{HbA} 1 \mathrm{c}$ level were associated with higher odds of basal-bolus regimen for $\mathrm{BI}$ initiation. Those findings further reflect a delay of insulin initiation which lead to an initiation of basal-bolus. We found that in patients with at least one complication, basal-bolus showed higher glycemic control rate than those with BI only only in those with $\mathrm{HbA} 1 \mathrm{c} \geq 9 \%$ and $\geq 2$ OADs used before, but with no significance. However, basal-bolus showed lower glycemic control rate in those with $\mathrm{HbA} 1 \mathrm{c}<9 \%$ ( $1 \mathrm{OAD}$ or $\geq 2 \mathrm{OADs}$ ) or $\mathrm{HbA} 1 \mathrm{c} \geq 9 \%$ (1 OAD). Those findings suggest that initiating basal-bolus may not be a better choice than BI only to attain glycemic target in patients who already have had one or more complications unless their $\mathrm{HbA} 1 \mathrm{c}$ is no less than $9 \%$ and two or more OADs have been used. Nevertheless, in patients with no complication, although the overall glycemic control was lower in basal-bolus than $\mathrm{BI}$ only, basal-bolus showed higher glycemic control than $\mathrm{BI}$ only in those with $\mathrm{HbA1c}<$ $9 \%$ and $\geq 2 \mathrm{OAD}, \mathrm{HbA} 1 \mathrm{c} \geq 9 \%$ and one $\mathrm{OAD}$, and $\mathrm{HbA} 1 \mathrm{c} \geq 9 \%$ and $\geq 2 \mathrm{OAD}$ unless their $\mathrm{HbA} 1 \mathrm{c}$ was less than $9 \%$ and only one OADs has been used. Therefore, basal-bolus might be an alternative for insulin initiation in patients with no complication unless their $\mathrm{HbA} 1 \mathrm{c}$ is less than $9 \%$ and only one OAD has been used before. Moreover, it would be initially challenging and burdensome for them to immediately transit from one $O A D$ to a complex regimen of basal-bolus insulin, which may compromise patients' adherence.

As achieving timely tight glycemic control is key to optimizing clinical outcomes and delayed insulin initiation may result in suboptimal glycemic control, overcoming clinical inertia of insulin initiation is important for diabetes management. Education of patients about the long-term benefits of lowering their blood glucose and training on how best to achieve this, convenient and well-tolerated insulin therapies with a low risk of hypoglycemia and weight gain, ${ }^{(33)}$ and a patient-driven insulin titration regimens ${ }^{(34)}$ may help patients to initiate insulin therapy timely and increase their adherence to it. 
In addition, older age, number of concomitant OADs, and insulin of detemir and glargine were associated with lower odds of basal-bolus insulin. Compared with BI only, initiating basal-bolus might be associated with a higher risk of hypoglycemia and more weight gain in spite of better anti-hyperglycemic effect. ${ }^{(35)}$ Therefore, an insulin regimen of BI only may be preferred for older patients initiating insulin therapy. As some OADs may further lead to side effects such as hypoglycemia and weight gain, ${ }^{23,25)}$ which also increased the therapy regimen's complexity, their use was reduced in a basal-bolus therapy. A previous study reported equivalent glycemic control and hypoglycemia in basal-bolus regimen with insulin analogues compared to basal-bolus regimen with human insulin in hospitalized patients with diabetes.

(36) The higher cost of detemir and glargine might also partly explain their reduced association with basal-bolus therapy compared with NPH.

Current guidelines recommend a routine of antihyperglycemic therapy in patients with T2DM where basal-bolus insulin as combination injectable therapy is usually initiated after triple therapy consisting of lifestyle management, metformin and two additional agents. ${ }^{(8,9)}$ However, our study observed that patients with one OAD used before were more likely to initiate basal-bolus insulin than those with two or more OADs used before, even after stratified by having complications or not, and $\mathrm{HbA} 1 \mathrm{c}$ level $(<9.0 \%$ or $\geq 9.0 \%$ ). The reason behind this was unknown. It might be because patients with one OAD and those with two or more OADs used before both tended to keep their previous OAD regimen, and the higher number of concomitant OADs was associated with lower odds of basal-bolus insulin. Also, patients with only one OAD before might have a previously higher glycemia than those with two or more OADs, so they tended to initiate basal-bolus rather than BI only.

Although the present study is based on a large nationally representative sample of Chinese T2DM with insufficient glycemic control by OADs, it is important to consider the results of this study in light of some limitations. First, we only included T2DM patients who were willing to use BI at their insulin initiation, while those willing to initiate other types of insulin such as bolus or premix insulin were excluded. Given that premix insulin is also an option for insulin initiation, further study involving premix insulin would help us picture a more representative insulin initiation status in China. Second, the inclusion criteria of HbA1c level was $7 \%$ or higher, which missed those who initiated $\mathrm{BI}$ with a $\mathrm{HbA} 1 \mathrm{c}$ level lower than $7 \%$, therefore the mean level of $\mathrm{HbA} 1 \mathrm{c}$ at insulin initiation might be overestimated. Third, the cross-sectional nature of our study limited causal association between some factors and basal-bolus.

\section{Conclusion}

In conclusion, this study suggests a high proportion of patients with T2DM initiating basal-bolus insulin. Tertiary hospital, in-patients, younger age, higher BMI, longer diabetes duration, more complications, higher HbA1c level, low SMBG frequency before, one OAD used before, no concomitant OAD, and concomitant NPH were related to higher odds of initiating basal-bolus.

\section{List Of Abbreviations}


$\mathrm{BI}$

Basal insulin

BMI

Body mass index

FPG

Fasting plasma glucose

HbA1c

Hemoglobin A1c

$\mathrm{NPH}$

Neutral Protamine Hagedorn

OADs

Oral antidiabetic drugs

ORBIT

Observational Registry of Basal Insulin Treatment

SMBG

Self-monitoring of blood glucose

T2DM

Type 2 diabetes mellitus

\section{Declarations}

\section{Ethics approval and consent to participate}

The ethics was approved by the Institutional Review Board of Peking University and, when necessary, also approved by local Institutional Review Boards. Written informed consent was provided to all the participants in this study.

\section{Consent for publication}

Not applicable

\section{Availability of data and materials}

The datasets used and/or analysed during the current study are available from the corresponding author on reasonable request.

\section{Competing interests}

The authors declare that there is no conflict of interest regarding the publication of this paper.

\section{Funding}


This study was funded by Sanofi-Aventis (Shanghai, China). The funder had no role in the design and conduct of the study, nor the decision to submit the manuscript for publication.

\section{Authors' contributions}

L.J and P.Z. contributed to the study design, conduct, and data interpretation. X.L. and J.J. contributed to the data analysis. H.Z. and D.Z. contributed to the drafting of the manuscript. All authors contributed to the acquisition and/or interpretation of the data and critically read the manuscript, suggested revisions, and approved the final version of the manuscript.

\section{Acknowledgments}

The authors wish to acknowledge Professor Laurent Billot at Statistics Division in the University of New South Wales for his suggestions on data analysis and English language editing of this manuscript.

\section{References}

1. Wajchenberg BL. beta-cell failure in diabetes and preservation by clinical treatment. Endocrine reviews. 2007;28(2):187-218.

2. Owens DR. Stepwise intensification of insulin therapy in type 2 diabetes management--exploring the concept of the basal-plus approach in clinical practice. Diabetic medicine : a journal of the British Diabetic Association. 2013;30(3):276-88.

3. Lovre D, Fonseca V. Benefits of timely basal insulin control in patients with type 2 diabetes. Journal of diabetes and its complications. 2015;29(2):295-301.

4. Intensive blood-glucose control with sulphonylureas or insulin compared with conventional treatment and risk of complications in patients with type 2 diabetes (UKPDS 33). UK Prospective Diabetes Study (UKPDS) Group. Lancet. 1998;352(9131):837-53.

5. Holman RR, Paul SK, Bethel MA, Matthews DR, Neil HA. 10-year follow-up of intensive glucose control in type 2 diabetes. The New England journal of medicine. 2008;359(15):1577-89.

6. Vinik A. Advancing therapy in type 2 diabetes mellitus with early, comprehensive progression from oral agents to insulin therapy. Clinical therapeutics. 2007;29(6 Pt 1):1236-53.

7. Xu Y, Wang L, He J, Bi Y, Li M, Wang T, et al. Prevalence and control of diabetes in Chinese adults. Jama. 2013;310(9):948-59.

8. CDS. Chinese Guideline for Type 2 Diabetes (2017). Chin Journal of Diabetes Mellitus. 2017 (in Chinese);10(1):2-67.

9. American Diabetes A. 8. Pharmacologic Approaches to Glycemic Treatment: Standards of Medical Care in Diabetes-2018. Diabetes care. 2018;41(Suppl 1):S73-S85.

10. Holman RR, Farmer AJ, Davies MJ, Levy JC, Darbyshire JL, Keenan JF, et al. Three-year efficacy of complex insulin regimens in type 2 diabetes. The New England journal of medicine. 2009;361(18):1736-47. 
11. Owens DR, Luzio SD, Sert-Langeron C, Riddle MC. Effects of initiation and titration of a single preprandial dose of insulin glulisine while continuing titrated insulin glargine in type 2 diabetes: a 6month 'proof-of-concept' study. Diabetes, obesity \& metabolism. 2011;13(11):1020-7.

12. Ji L, Zhang P, Weng J, Lu J, Guo X, Jia W, et al. Observational Registry of Basal Insulin Treatment (ORBIT) in Patients with Type 2 Diabetes Uncontrolled by Oral Hypoglycemic Agents in China-Study Design and Baseline Characteristics. Diabetes Technol Ther. 2015;17(10):735-44.

13. Kim SS, Kim IJ, Kim YK, Yoon KH, Son HY, Park SW, et al. Insulin Initiation in Insulin-Naive Korean Type 2 Diabetic Patients Inadequately Controlled on Oral Antidiabetic Drugs in Real-World Practice: The Modality of Insulin Treatment Evaluation Study. Diabetes \& metabolism journal. 2015;39(6):4818.

14. Patrick AR, Fischer MA, Choudhry NK, Shrank WH, Seeger JD, Liu J, et al. Trends in insulin initiation and treatment intensification among patients with type 2 diabetes. Journal of general internal medicine. 2014;29(2):320-7.

15. Blackberry ID, Furler JS, Ginnivan LE, Manski-Nankervis JA, Jenkins A, Cohen N, et al. An exploratory trial of basal and prandial insulin initiation and titration for type 2 diabetes in primary care with adjunct retrospective continuous glucose monitoring: INITIATION study. Diabetes research and clinical practice. 2014;106(2):247-55.

16. Orozco-Beltran D, Pan C, Svendsen AL, Faerch L, Caputo S, Group SS. Basal insulin initiation in primary vs. specialist care: similar glycaemic control in two different patient populations. International journal of clinical practice. 2016;70(3):236-43.

17. Tsai ST, Pathan F, Ji L, Yeung VT, Chadha M, Suastika K, et al. First insulinization with basal insulin in patients with Type 2 diabetes in a real-world setting in Asia. Journal of diabetes. 2011;3(3):208-16.

18. Abrahamson MJ, Peters A. Intensification of insulin therapy in patients with type 2 diabetes mellitus: an algorithm for basal-bolus therapy. Annals of medicine. 2012;44(8):836-46.

19. Bergenstal RM, Johnson M, Powers MA, Wynne A, Vlajnic A, Hollander P, et al. Adjust to target in type 2 diabetes: comparison of a simple algorithm with carbohydrate counting for adjustment of mealtime insulin glulisine. Diabetes care. 2008;31(7):1305-10.

20. Davis NJ, Wylie-Rosett J. Death to carbohydrate counting? Diabetes care. 2008;31(7):1467-8.

21. Raccah D, Haak TJ, Huet D, Monnier L, Robertson D, Labard P, et al. Comparison of stepwise addition of prandial insulin to a basal-bolus regimen when basal insulin is insufficient for glycaemic control in type 2 diabetes: results of the OSIRIS study. Diabetes \& metabolism. 2012;38(6):507-14.

22. Rodbard HW, Visco VE, Andersen H, Hiort LC, Shu DH. Treatment intensification with stepwise addition of prandial insulin aspart boluses compared with full basal-bolus therapy (FullSTEP Study): a randomised, treat-to-target clinical trial. The lancet Diabetes \& endocrinology. 2014;2(1):30-7.

23. Nathan DM, Buse JB, Davidson MB, Ferrannini E, Holman RR, Sherwin R, et al. Medical management of hyperglycaemia in type 2 diabetes mellitus: a consensus algorithm for the initiation and adjustment of therapy: a consensus statement from the American Diabetes Association and the European Association for the Study of Diabetes. Diabetologia. 2009;52(1):17-30. 
24. National Institute for Health and Clinical Excellence. T2DM: the management of T2DM. NICE clinical guideline. National Institute for Health and Care Excellence: Clinical Guidelines2015.

25. Weng J, Ji L, Jia W, Lu J, Zhou Z, Zou D, et al. Standards of care for type 2 diabetes in China. Diabetes Metab Res Rev. 2016;32(5):442-58.

26. Umpierrez GE, Hellman R, Korytkowski MT, Kosiborod M, Maynard GA, Montori VM, et al. Management of hyperglycemia in hospitalized patients in non-critical care setting: an endocrine society clinical practice guideline. The Journal of clinical endocrinology and metabolism. 2012;97(1):16-38.

27. Moghissi ES, Korytkowski MT, DiNardo M, Einhorn D, Hellman R, Hirsch IB, et al. American Association of Clinical Endocrinologists and American Diabetes Association consensus statement on inpatient glycemic control. Diabetes care. 2009;32(6):1119-31.

28. Cook CB, Castro JC, Schmidt RE, Gauthier SM, Whitaker MD, Roust LR, et al. Diabetes care in hospitalized noncritically ill patients: More evidence for clinical inertia and negative therapeutic momentum. Journal of hospital medicine. 2007;2(4):203-11.

29. Umpierrez GE, Smiley D, Hermayer K, Khan A, Olson DE, Newton C, et al. Randomized study comparing a Basal-bolus with a basal plus correction insulin regimen for the hospital management of medical and surgical patients with type 2 diabetes: basal plus trial. Diabetes care. 2013;36(8):2169-74.

30. Umpierrez GE, Smiley D, Jacobs S, Peng L, Temponi A, Mulligan P, et al. Randomized study of basalbolus insulin therapy in the inpatient management of patients with type 2 diabetes undergoing general surgery (RABBIT 2 surgery). Diabetes care. 2011;34(2):256-61.

31. Umpierrez GE, Hor T, Smiley D, Temponi A, Umpierrez D, Ceron M, et al. Comparison of inpatient insulin regimens with detemir plus aspart versus neutral protamine hagedorn plus regular in medical patients with type 2 diabetes. The Journal of clinical endocrinology and metabolism. 2009;94(2):564-9.

32. Bellido V, Suarez L, Rodriguez MG, Sanchez C, Dieguez M, Riestra M, et al. Comparison of BasalBolus and Premixed Insulin Regimens in Hospitalized Patients With Type 2 Diabetes. Diabetes care. 2015;38(12):2211-6.

33. Khunti K, Millar-Jones D. Clinical inertia to insulin initiation and intensification in the UK: A focused literature review. Primary care diabetes. 2016.

34. LaSalle JR. Empowering patients during insulin initiation: a real-world approach. The Journal of the American Osteopathic Association. 2010;110(2):69-78.

35. Petznick A. Insulin management of type 2 diabetes mellitus. Am Fam Physician. 2011;84(2):183-90.

36. Bueno E, Benitez A, Rufinelli JV, Figueredo R, Alsina S, Ojeda A, et al. Basal-Bolus Regimen with Insulin Analogues Versus Human Insulin in Medical Patients with Type 2 Diabetes: A Randomized Controlled Trial in Latin America. Endocr Pract. 2015;21(7):807-13.

\section{Tables}


Table 1. Baseline characteristics of patients by insulin regimen 


\begin{tabular}{|c|c|c|c|c|}
\hline Baseline characteristics & Total (\%) & Only BI (\%) & Basal-bolus (\%) & P-value \\
\hline Overall & 18995 (100.0) & $14321(75.4)$ & $4674(24.6)$ & \\
\hline Region & & & & $<.0001$ \\
\hline Northeast & 8.8 & 6.9 & 14.7 & \\
\hline North coast & 17.2 & 15.2 & 23.6 & \\
\hline Yellow River & 14.9 & 14.5 & 16.2 & \\
\hline South coast & 10.5 & 10.3 & 10.9 & \\
\hline Southwest & 15.3 & 16.0 & 13.3 & \\
\hline East coast & 11.9 & 13.0 & 8.8 & \\
\hline Yangtze River & 15.9 & 17.3 & 11.6 & \\
\hline Northwest & 5.5 & 6.9 & 1.1 & \\
\hline Hospital level & & & & $<.0001$ \\
\hline Secondary Hospital & 49.7 & 48.3 & 54.1 & \\
\hline Tertiary Hospital & 50.3 & 51.7 & 45.9 & \\
\hline Patient recruitment settings & & & & $<.0001$ \\
\hline Out-patient clinic & 44.0 & 52.3 & 18.5 & \\
\hline In-patient ward & 56.0 & 47.7 & 81.5 & \\
\hline Age (years), mean $\pm \mathrm{SD}$ & $55.4 \pm 10.4$ & $55.7 \pm 10.4$ & $55.5 \pm 10.2$ & 0.0046 \\
\hline Male & 52.5 & 52.8 & 51.4 & \\
\hline Education level & & & & $<.0001$ \\
\hline Primary school or lower & 27.1 & 25.9 & 30.8 & \\
\hline Junior high school & 30.8 & 30.2 & 32.9 & \\
\hline Senior middle school & 24.9 & 25.4 & 23.2 & \\
\hline Junior college or higher & 17.1 & 18.5 & 13.1 & \\
\hline $\mathrm{BMI}\left(\mathrm{kg} / \mathrm{m}^{2}\right)$, mean $\pm \mathrm{SD}$ & $24.7 \pm 3.4$ & $24.7 \pm 3.3$ & $24.6 \pm 3.4$ & $<.0001$ \\
\hline Diabetes duration (years), mean $\pm \mathrm{SD}$ & $6.4 \pm 5.3$ & $6.1 \pm 5.0$ & $6.9 \pm 5.8$ & $<.0001$ \\
\hline Number of complications in the past & & & & $<.0001$ \\
\hline 0 & 63.6 & 66.5 & 54.9 & \\
\hline 1 & 21.3 & 20.4 & 24.1 & \\
\hline
\end{tabular}




\begin{tabular}{|c|c|c|c|c|}
\hline Baseline characteristics & Total (\%) & Only BI (\%) & Basal-bolus (\%) & P-value \\
\hline 2 & 10.2 & 9.1 & 13.7 & \\
\hline$\geq 3$ & 4.8 & 4.0 & 7.3 & \\
\hline Total times of SMBG last month (median, IQR) & $2.0(5.0)$ & $1.0(4.0)$ & $2.0(6.0)$ & $<.0001$ \\
\hline HbA1c (\%), mean \pm SD & $9.6 \pm 2.0$ & $9.3 \pm 1.8$ & $10.4 \pm 2.1$ & $<.0001$ \\
\hline $\mathrm{FPG}(\mathrm{mmol} / \mathrm{L})$, mean $\pm \mathrm{SD}$ & $11.7 \pm 4.0$ & $11.2 \pm 3.7$ & $12.9 \pm 4.7$ & $<.0001$ \\
\hline missing & 754 & 556 & 188 & \\
\hline General hypoglycemia (past month) & 5.6 & $832(5.1)$ & $237(5.8)$ & 0.0570 \\
\hline $\mathrm{OAD}$ treatment duration (years), mean $\pm \mathrm{SD}$ & $5.7 \pm 5.1$ & $5.4 \pm 4.7$ & $6.0 \pm 5.5$ & $<.0001$ \\
\hline Number of OAD type before baseline & & & & $<.0001$ \\
\hline 1 & 46.0 & 43.1 & 55.0 & \\
\hline 2 & 44.1 & 46.1 & 38.0 & \\
\hline$\geq 3$ & 9.9 & 10.8 & 7.1 & \\
\hline Number of OAD type at baseline & & & & $<.0001$ \\
\hline 0 & 20.4 & 7.4 & 60.1 & \\
\hline 1 & 42.8 & 46.6 & 31.3 & \\
\hline 2 & 30.3 & 37.9 & 7.3 & \\
\hline$\geq 3$ & 6.5 & 8.2 & 1.3 & \\
\hline Type of BI & & & & $<.0001$ \\
\hline Glargine & 70.0 & 74.5 & 56.1 & \\
\hline Detemir & 12.6 & 12.9 & 11.5 & \\
\hline $\mathrm{NPH}$ & 17.5 & 12.6 & 32.4 & \\
\hline Injection number of bolus insulin at baseline & & & & - \\
\hline 1 & 0.8 & - & 0.8 & \\
\hline 2 & 1.4 & - & 1.4 & \\
\hline 3 & 97.8 & - & 97.8 & \\
\hline
\end{tabular}

BI: basal insulin; FPG: fasting plasma glucose; OAD: oral antidiabetic drugs; BMI: body mass index; SMBG: self-monitoring blood glucose; IQR: inter-quartile range. 
Table 2. Multivariate logistic regression analyses of factors associated with initiating basal-bolus 


\begin{tabular}{|c|c|c|}
\hline Associated factors & Adjusted OR (95\%CI)* & $\mathrm{P}$-value \\
\hline In-patient vs out-patient & $5.666(5.067-6.336)$ & $<.0001$ \\
\hline Tertiary hospital vs secondary hospital & $1.257(1.143-1.382)$ & $<.0001$ \\
\hline Age & $0.993(0.988-0.998)$ & 0.0031 \\
\hline BMI & $1.020(1.006-1.034)$ & 0.0054 \\
\hline Diabetes duration (years) & $1.032(1.023-1.042)$ & $<.0001$ \\
\hline \multicolumn{3}{|l|}{ Complications (vs 0) } \\
\hline 1 & $1.052(0.937-1.182)$ & 0.0085 \\
\hline$\geq 2$ & $1.503(1.320-1.711)$ & $<.0001$ \\
\hline HbA1c level (\%) & $1.330(1.300-1.361)$ & $<.0001$ \\
\hline Times of SMBG last month (times per month) & $0.987(0.982-0.992)$ & $<.0001$ \\
\hline \multicolumn{3}{|l|}{ Number of OAD type before baseline (vs 1) } \\
\hline 2 & $0.663(0.610,0.721)$ & $<.0001$ \\
\hline$\geq 3$ & $0.540(0.465,0.627)$ & $<.0001$ \\
\hline \multicolumn{3}{|l|}{ Number of OAD type at baseline (vs 0 ) } \\
\hline 1 & $0.081(0.072-0.090)$ & 0.0003 \\
\hline 2 & $0.020(0.017-0.023)$ & $<.0001$ \\
\hline$\geq 3$ & $0.013(0.010-0.018)$ & $<.0001$ \\
\hline \multicolumn{3}{|l|}{ Type of BI (vs NPH) } \\
\hline Detemir & $0.280(0.248-0.317)$ & $<.0001$ \\
\hline Glargine & $0.407(0.345-0.480)$ & 0.0002 \\
\hline
\end{tabular}

Variables included in the model were geographic region, hospital level (secondary or tertiary), patient recruitment setting (inpatient or outpatient clinic), age, gender, ethnicity, education level, type of registered residence (rural or urban), BMI, duration of diabetes, number of complications, HbA1c, fasting plasma glucose, SMBG frequency, severe and general hypoglycemia, number of OAD type before and at baseline, and type of BI. Final variables were selected by a stepwise method, with geographic regions as an adjustment variable. 
Table 3. Proportion of patients initiating basal-bolus by complications, HbA1c level and previous OAD number

\begin{tabular}{|c|c|c|c|c|c|}
\hline cations & HbA1c (\%) & Previous OAD number & Total & Basal-bolus, N (\%) & P-value \\
\hline \multirow[t]{4}{*}{ Jo } & $<9$ & 1 & 2419 & $358(14.8)$ & $<0.0001$ \\
\hline & & $\geq 2$ & 2889 & $308(10.7)$ & \\
\hline & $\geq 9$ & 1 & 3399 & 1118 (32.9) & $<0.0001$ \\
\hline & & $\geq 2$ & 3382 & $784(23.2)$ & \\
\hline \multirow[t]{4}{*}{ es } & $<9$ & 1 & 1302 & $322(24.7)$ & $<0.0001$ \\
\hline & & $\geq 2$ & 1922 & $332(17.3)$ & \\
\hline & $\geq 9$ & 1 & 1621 & $772(47.6)$ & $<0.0001$ \\
\hline & & $\geq 2$ & 2061 & $680(33.0)$ & \\
\hline
\end{tabular}

\section{Figures}

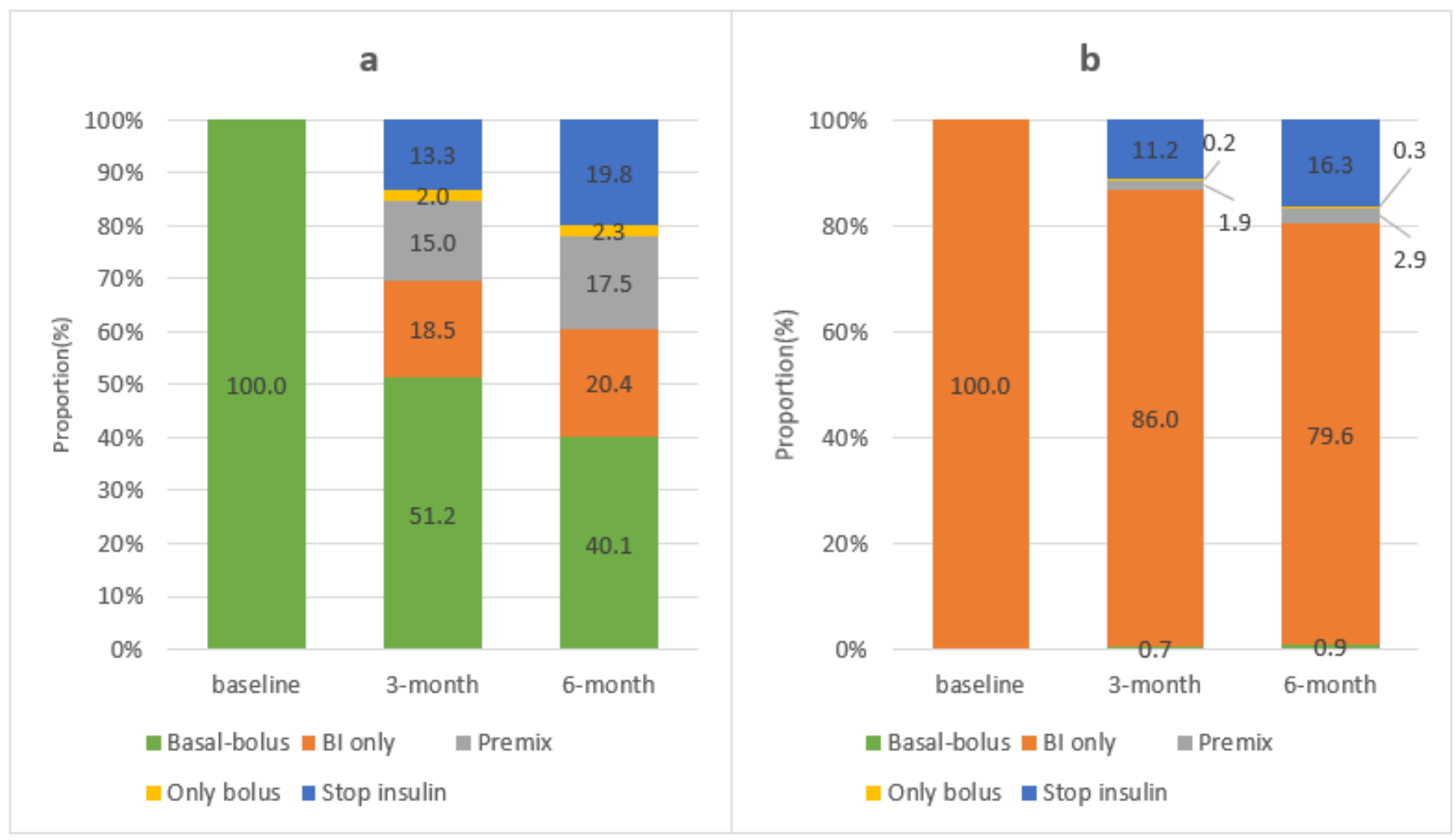

Figure 1 
Proportion of patients changing insulin regimen at 3-month and 6-month after initiating basal insulin. Legends: a) Of the 4,674 patients initiating basal-bolus, 4,252 and 3,983 were followed at 3-month and 6month, in which around 40 percent persisted in this regimen at 6-month, whereas more than 30 percent switched to only BI or premix insulin; about 2 percent switched to only bolus insulin; and nearly 20 percent stopped insulin therapy at 6-month. b) Of the 14,321 patients initiating BI only, 13,001 and 12,358 were followed at 3-month and 6-month, in which about 80 percent persisted in this regimen at 6-month, whereas 4.1 percent switched to other insulin regimens (premixed $2.9 \%$; basal-bolus $0.9 \%$; only bolus $0.3 \%)$; and 16.3 percent stopped insulin therapy at 6-month. 


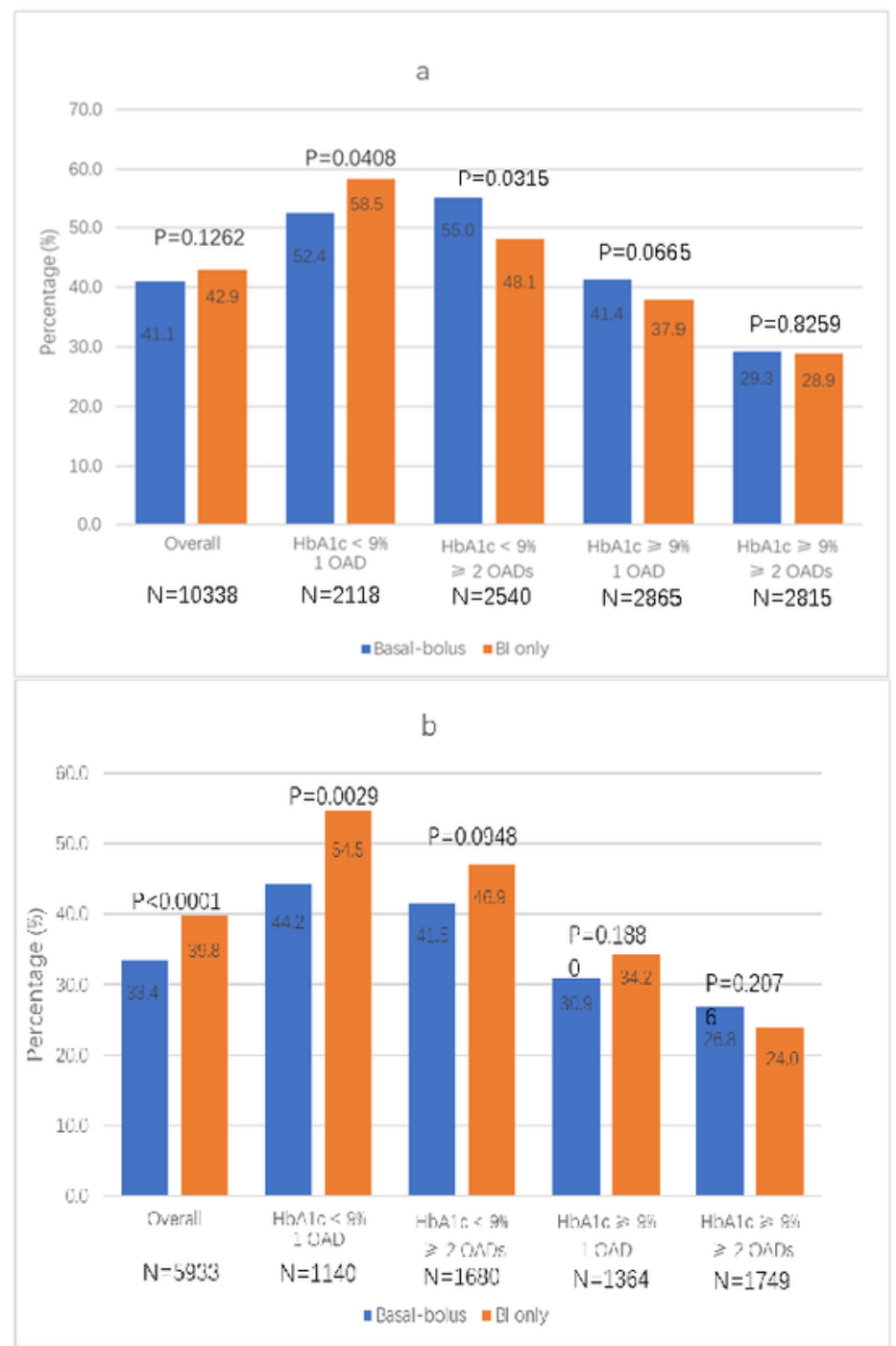

Figure 2

Percentages of patients without/with complication reaching $\mathrm{HbA} 1 \mathrm{c}<7 \%$ at 6 -month for overall patients and subgroups. Legends: a) Of 10,338 patients with no complication, the overall glycemic control rate was lower in those with basal-bolus than those with basal insulin (BI) alone but with no significance. Compared with patients taking BI only, basal-bolus showed significantly lower glycemic control rate in those with $\mathrm{HbA} 1 \mathrm{c}<9 \%$ and one OAD used before, whereas basal-bolus showed higher glycemic control 
rates in those with $\mathrm{HbA} 1 \mathrm{c}<9 \%$ and $\geq 2 \mathrm{OAD}, \mathrm{HbA} 1 \mathrm{c} \geq 9 \%$ and one $\mathrm{OAD}$ ) and $\mathrm{HbA} 1 \mathrm{c} \geq 9 \%$ and $\geq 2 \mathrm{OAD}$. b) Of 5933 patients with at least one complication, the overall glycemic control rate was significantly lower in patients with basal-bolus than those with BI only. Compared with BI only, basal-bolus showed lower glycemic control rates in those with $\mathrm{HbA} 1 \mathrm{c}<9 \%$ and one OAD used before, $\mathrm{HbA} 1 \mathrm{c}<9 \%$ and $\geq 2 \mathrm{OAD}$, and $H b A 1 c \geq 9 \%$ and one $O A D$, except in those with $H b A 1 c \geq 9 \%$ and $\geq 2$ OAD. 